\title{
Fungi-rice bran based Fermentation of Coptis Chinensis and Curcuma Longa Root and its Influence of Silk Dyeing
}

\author{
Young Mi Park ${ }^{1) \dagger}$ and Jae Hong Choi $^{2)}$ \\ ${ }^{1)}$ Dept. of Clothing \& Fashion, Yeungnam University, Gyeongsan, Korea \\ ${ }^{2)}$ Dept. of Biomolecule \& Chemical Engineering, Dongyang University; Yeongju, Korea
}

\begin{abstract}
This study examined the dye-properties of natural fabrics dyed with Coptis chinensis and Curcuma longa root fermented with fungi. The optimum culture conditions for the fermentation of microorganisms, the relationship between natural dye color and fermentation conditions were investigated. Two different medical herbs (ground to 80-100 mesh in size) were used as a natural dyeing source. Phellinus linteus (P. linteus), which can grow in different media, such as Agarmedium (only agar containing medium), maltose extract agar (MA) and potato dextrose extract agar (PDA) culture media, were isolated from the medium. P. linteus was confirmed to be the optimum microorganism for the fermentation of Coptis chinensis and Curcuma longa, and the MA medium was confirmed to be the best for culturing. When using the microorganism as the fermenting agent, $32^{\circ} \mathrm{C}$ was found to be the optimum fermenting temperature for both natural colorants. Regarding the dyeing property of the fermented natural dye, silk was dyed quite darkly in an appearance by naked eye estimation and the K/S value in the color strength of silk reached a high level of 16 after the fermenting process. The washing fastness of dyed silk after treatment washing was reduced from 4 to under4 and indicates that dyed silk with fermented plant was not unsubstantial. The light fastness was 1 to 2 , showing intended to maintain due to the fermentation process.
\end{abstract}

Key words: coloration, fungal fermentation, coptis chinensis, curcuma longa root, fermented natural dye

\section{Introduction}

Recently, consumers have shown growing interest in pursuing the LOHAS trend for natural color and environmental reasons. On the other hand, almost plant dyes used for natural dyeing have a lower affinity to fibers and less durable after dyeing due to denature that occurs during the dyeing process. Natural dyeing enthusiasts often perform dyeing room temperature and ferment it naturally to prevent the metamorphosis of plant dyes by the surrounding conditions. Nevertheless, there has been rarely study on fermented dyes according to the fungi and culture, while in my previous paper, the dyeing properties of fabrics was examined on the coloration with fermented several plants when the formation of plant not fungi but malt (Park, 2012a). Fermentation is a process where microorganisms create alcohols, organic acids and carbon dioxide as the residual products using carbohydrate as the energy source. Reaction of microorganisms to produce a certain substrate can be considered fermentation (Yu \& Beun, 2008). In the case of a product fermented from plant extracts using microorganism fermentation, a distinctive element is produced during the enzyme secretion

$\dagger$ Corresponding author; Youngmi Park

Tel. +82-53-810-2791, Fax. +82-53-810-4687

E-mail: ymp9397@yu.ac.kr process or an element in the raw material transforms to a new element and the hypotonicity is improved (Yu et al., 1999). Therefore, it is important to examine the fermentation characteristics of plant dyes by micro organisms and the potential use of fermented plants as dyeing materials through the color changes.

The plants used for the fermented dyeing materials in this study were Coptis chinensis (Coptis) and Curcuma longa (Curcuma), which are used mainly as materials for food additives. Figure 1 shows the chemical formula of the main dye components expected from these two plants (Chu \& Soh, 1996).

Fig. 1(a) shows the chemical structure of berberine, which is the main element in Coptis and an isoquinoline derivative that it is used for yellow dyeing (Lin \& Lin, 2011). Berberine also exhibits antiinflammatory (Lin \& Lin, 2011; Siow et al., 2011) and antifungal functions (Freile et al., 2003), has been used in the Chinese medicine to treat burns and control diabetes (Yin et al., 2012), and has

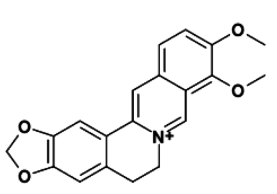

(a)<smiles>COc1cc(/C=C/C(=O)/C=C/c2ccc(O)c(OC)c2)ccc1O</smiles>

(b)
Fig. 1. Representative chemical structures of berberine (a) and curcumin (b) in Coptis and Curcuma. 
dyeing properties and anti-microbial functions (Cho, 2009; Eum, 2012).

The main ingredients of Curcuma are curcuminoid color pigments, such as curcuminand demethoxy curcumin, and volatile oil elements including arturmerone, curlone, $\alpha, \beta$-turmerone, bisacumol and zingiberene. Its root contains yellow color pigments composed of curcumin, which is a yellow crystalline substance, and its derivatives, along with oil, starch, crude fiber, ash and moisture (Park \& Cha, 1994). The main pharmaceutical substances of Curcuma come from curcuminoid, which is a biological active material with anti-inflammatory, anti-oxidant, antitumor and antifungal functions (Kim et al., 2005).

The roots of both Coptis and Curcuma are used for dyeing because they contain a relatively large quantity of yellow pigments and good fastness after dyeing. Coptis and Curcuma have medically beneficial ingredients and are harmless to the human body. Many researchers have reported the excellence of these plants, though, most of these studies focused on the dyeing property (Soh,1998; Cho et al., 1997), color stability(Hwang et al., 1998), anti-microbial function (Han et al., 2002) and biological activities (Ryu et al., 2005) of Curcuma and Coptis root, and except for the dyeing property, these results would not satisfy consumers. As with other natural dyes, the light durability is still the main problem, encouraging need for further researches.

This study examined the culture conditions using the plant root and Phellinus linteus (P. linteus) mixed to identify the optimal conditions for the growth and fermentation of microorganisms. Therefore, dye was fermented under these optimal temperature and humidity conditions, and extracted to determine its dyeing characteristics on silk fabrics.

\section{Experimental}

\subsection{Materials}

Scoured silk (satin weave; weight $42 \mathrm{~g} \cdot \mathrm{m}^{2}$; density $160 \times 98 \mathrm{inch}^{2}$; Thickness $0.11 \mathrm{~mm}$ ) was obtained commercially from local market in Daegu (Korea). The roots used for dyeing source were obtained from Coptis and Curcuma which purchased from OMNIHERB (Korea). After fermenting as received and then ground to an $80 \sim$ 100 mesh. The rice bran used for the nitrogen source was purchased from a rice mill in Sangju, Gyeongbuk, Korea. Alum (aluminum acetate; $\left.\mathrm{Al}\left(\mathrm{CH}_{2} \mathrm{COO}\right)_{3}\right)$ and copper acetate $\left(\left(\mathrm{CH}_{3} \mathrm{COO}\right)_{2}\right.$ $\left.\mathrm{Cu} \cdot \mathrm{H}_{2} \mathrm{O}\right)$ as mordants were of laboratory reagent grade, purchased from Duksan pure chemicals Co., Ltd. Agar, malt extract (MA), potato dextrose agar extract (PDA) and other materials were purchased from World Science Co., Ltd. (Korea). The used mushroom fungus was supplied by Korean Collection for Type Cultures
(KCTC). The strain number of $P$. linteus was KCTC 6190 and the source was from Phellinus mushroom.

\subsection{Preparation of natural dye and nitrogen source}

After sterilizing the prepared natural dye and endophytic fungi which exist in the rice bran (Hanshin Medical Co. Ltd, Gravity Type, Korea), $2 \mathrm{~g}$ of the natural dye and rice bran sterilized at $121^{\circ} \mathrm{C}$ for $15 \mathrm{~min}$ and unsterilized natural dye and rice bran with distilled water, were diluted by $50 \%$. The supernatant was obtained using a centrifuge. $5 \mu \mathrm{l}$ of the supernatant was injected into the MA and PDA medium, cultured in an incubator at $29^{\circ} \mathrm{C}$ and the clear zone ( $\mathrm{mm}$ ) was measured every 7 days to check the fungi condition of the schale.

\subsection{Preparation of growth medium and selection of} the culture medium by fungi culture

Solid MA and PDA medium were used as growth media. The solid medium was added to agar $1.5 \%$, sterilized at $121^{\circ} \mathrm{C}$ for 15 min, cooled it to $65^{\circ} \mathrm{C}$ in a clean bench, placed in the refrigerator at $4^{\circ} \mathrm{C}$ and the fungus was injected where necessary. P. linteus subcultured in MA and PDA medium was separated from the culturing spawn with a $2 \mathrm{~mm}$ punch and implanted at the center of the media containing the natural dye powder $(0.15 \%)$. The growth conditions in the incubator at $30^{\circ} \mathrm{C}$ were checked every 7 days.

\subsection{Optimal fermentation temperature and the content} of rice bran

To determine the effect of $P$. linteus, which was found the best fungus for the fermentation of root powder, the sterilized powder and rice bran were mixed as a mixing ratio of 50,70, 100, and $130 \%$. Next, $P$. linteus was injected, and then maintained in the varying incubator at $28^{\circ} \mathrm{C}, 30^{\circ} \mathrm{C}$, and $32^{\circ} \mathrm{C}$ to identify the best fermenting temperature for natural dye.

\subsection{Fermentation and extraction of dye}

The quick sterilized plant dye was cultured in a culture bath with $P$. linteus, and the content of 10 was mixed with distilled water, adding each of $5 \%$ nitrogen and carbon source (pH 5), and while maintaining a moisture content of the fermented powder of $20 \%$. For solid fermentation, the well mixed dye was placed in an incubator maintained at $32^{\circ} \mathrm{C}$ and $70 \%$ humidity for 15 days. Next, for liquid fermentation, the fermented dye powder was dried and $P$. linteus was sterilized rapidly at $121^{\circ} \mathrm{C}$ for $10 \mathrm{~min}$ in an autoclave and inserted into the fermentation bath. Then, 10 of aspergillus, which was used for liquid fermentation, was inserted into the fermenter and the fermentation was carried out at $32^{\circ} \mathrm{C}, \mathrm{pH} 5$. After fermentation, the dye powder was filtered, concentrated the solid content 
of 35 brix and kept in a refrigerator until used as a dye.

\subsection{Dyeingwith and without the mordant}

Dyeing was performed using an IR dyeing machine (KSL-24 PERFECT, Korea Science Co., Korea). Silk was dyed at a liquor ratio of $60: 1(\mathrm{~g} / \mathrm{ml})$, keeping the $\mathrm{pH}$ at medium state. The fabric was immersed when the temperature reached $30^{\circ} \mathrm{C}$. The temperature was then increased to $60^{\circ} \mathrm{C}$ and dyeing was performed at that temperature for $30 \mathrm{~min}$. The dyed fabrics were then rinsed with tap water, followed by soaping with $2 \mathrm{~g} \mathrm{~L}^{1}$ of a nonionic surfactant for household use (safe, LG Ltd., Korea) at room temperature. Finally the fabrics were washed thoroughly with water and dried over a 24 hrs. The methods of dyeing with the mordant were the same as that of the pre-mordant treatment. Two different mordants, aluminum acetate and sulfate, were used at a concentration of $3 \%(w / w)$, which is equal to $0.75 \mathrm{~g} \mathrm{~L}^{1}$. In the pre-mordant treatment, the fabrics were first immersed in an aqueous solution of the mordant for 30 $\min$ at $60^{\circ} \mathrm{C}$. All the mordant treated fabrics were then dyed using the above method. The fabrics were then rinsed, soaped with detergent, washed with distilled water and dried at room temperature.

\subsection{Color values of the dyed fabrics}

The X-Rite8200 color measurement system (X-Rite Co., USA) was used to measure the $\mathrm{K} / \mathrm{S}, \mathrm{L}$ (lightness), a (redness), $\mathrm{b}$ (yellowness), $\mathrm{h}$ (hue), and $\mathrm{C}$ (chroma) values of the fabrics with illuminant D65 and a visual angle $10^{\circ}$ standard observer system at 400-800 $\mathrm{nm}$. The system measured the difference in surface reflectance and calculated the relative color strength $(\mathrm{K} / \mathrm{S}$ value) using the Kubelka-Munk equation as following; $K / S=(1-R)^{2} / 2 R$, where $\mathrm{K}$ and $\mathrm{S}$ refers absorption and scattering coefficient and $\mathrm{R}$ is the reflectance of the dyed material at the maximum absorption wavelength, respectively.

The color difference $(\Delta E)$ based on $\mathrm{L}^{*}, \mathrm{a}^{*}, \mathrm{~b}^{*}$ and hue angle was determined using the modified CIELAB2000 formula equation (Hong et al., 2006).

\subsection{Fastness to washing and light test}

The light fastness of the dyed fabrics with and without fermen-
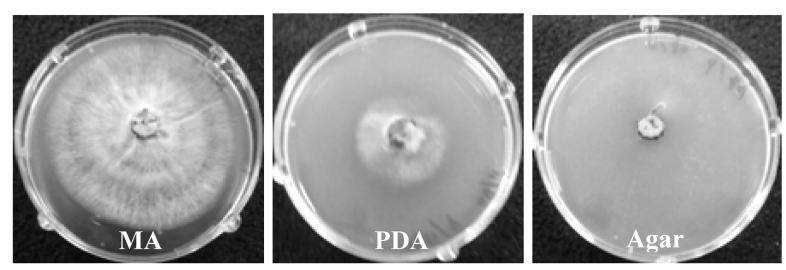

Fig. 2. P. linteus growth depending on the various media: MA (maltose extract agar), PDA (potato dextrose extract agar) and Agar-medium (only agar containing medium).

tation and mordant were evaluated using a Carbon-Arc Fade-Ometer (Atlas Device Electronic Co., USA) according to the KS K ISO 105 B-02: 2010 methods. To measure the K/S value, the specific tests for color characteristics before and after washing were tested using a Launder-O-meter (Atlas LP-2, USA) and the fastness to washing was investigated in compliance with KS K ISO 105C06: 2007.

\section{Results and Discussion}

3.1. Selection of the growth medium and culture medium of $P$. linteus by fungi culture

As a result of testing the fungus subcultured in the MA and PDA medium, $P$. linteus showed good growth in the MA medium without secondary metabolites, as shown in Fig. 2, and did not grow at all in the agar medium and PDA medium.

\subsection{Comparison of the growth of fungus according to} the natural dye powder content

The growth of $P$. linteus in Coptis powder differed according to the content $(0.2,1,2,4,6$ and 8\%), as shown in Fig. 3. The clear zone $(\mathrm{mm})$ near the disc was measured every 7 days to compare the growth of the fungus according to the Coptis powder content. As the Coptis powder content increased, the growth of $P$. linteus was suppressed, and when the dye powder content over $6 \%$ was added, the medium cracked and the growth of fungus could not be measured.

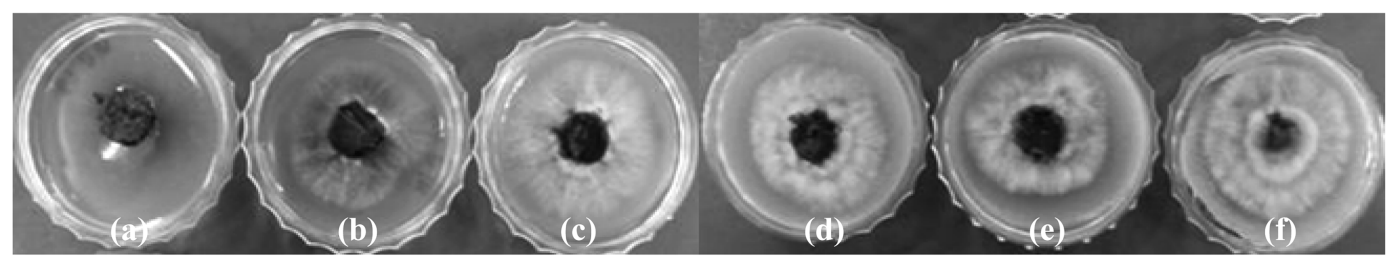

Fig. 3. Potential candidates for Coptis fermentation show different growth patterns according to its contents. Coptis powder with agar medium was applied. The powder amounts were (a) 0.2 , (b) 1, (c) 2, (d) 4, (e) 6 , and (f) $8 \%$. 

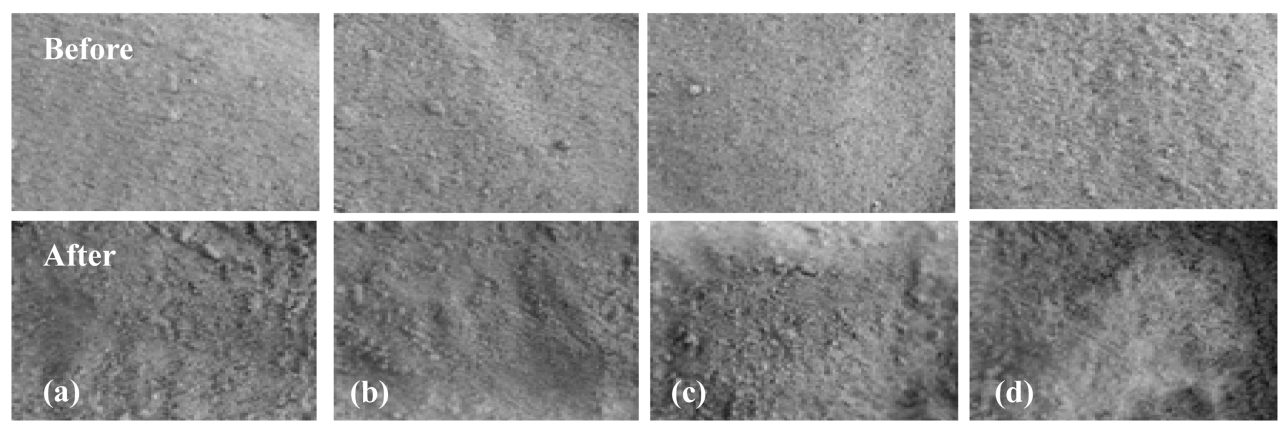

Fig. 4. Photograph of Curcuma powder before and after fermentation with different contents of rice bran in the media $50 \%(a), 70 \%(b), 100 \%(c)$ and $130 \%(\mathrm{~d})$ with $P$. linteus at $32^{\circ} \mathrm{C}$.
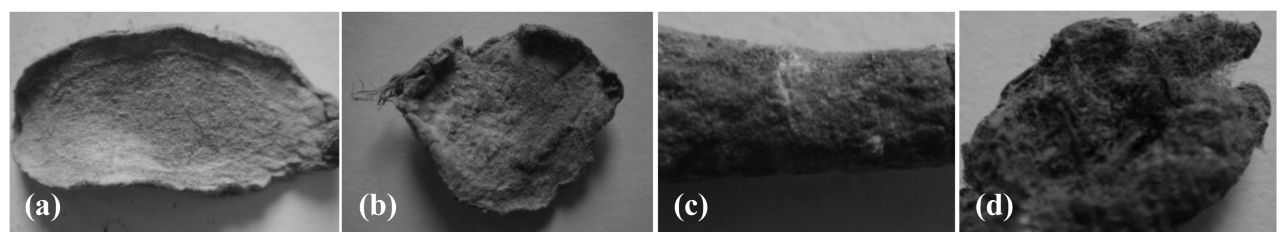

Fig. 5. Surface shapes of Coptis and Curcuma root before and after fermentation with P. linteus at $32^{\circ} \mathrm{C}$; before Coptis (a), after Coptis (b), before Curcuma (c), after Curcuma (d).

\subsection{Comparison of fermentation according to the rice bran content}

To determine the optimal rice bran content for the optimum fermentation conditions, Curcuma powder was mixed with rice bran at mixing ratios of $50,70,100$ and $130 \%$. P. linteus $\left(1 \times 10^{7}\right.$ spores) was injected and the powder conditions were observed. The mixture of Curcuma powder and rice bran at mixing ratios of 50, 70, 100, and $130 \%$ per $100 \mathrm{~g}$ of Curcuma powder showed satisfactory fermenting conditions, as shown in Fig. 4. On the other hand, fermentation was delayed or suppressed when the mixing ratio of rice bran content was more than $130 \%$. When the fermentation of the dye powder was observed at a relative humidity of $80 \%$ and different temperature at $28^{\circ} \mathrm{C}, 30^{\circ} \mathrm{C}$ and $32^{\circ} \mathrm{C}$, which the fungi showed the most active growth at $32^{\circ} \mathrm{C}$ but fermented relatively stable at $28^{\circ} \mathrm{C}$ and $30^{\circ} \mathrm{C}$. Consequently, $32^{\circ} \mathrm{C}$ was determined to be the best fermenting temperature of the two plant root in this study. Fig. 5 also present Tumeric root before and after fermentation with $P$. linteus at $32^{\circ} \mathrm{C}$. As seen in Fig. 5, we found the fermented material was covered with white mold. These results mean that the microorganism well react with plant but denature. From this fermentation, extracted dye would be contributed stable coloring on fabrics.

\subsection{Color characteristics of Coptis and Curcuma dyed silk fabrics}

After dyeing the fabrics with the dyeing materials extracted from fermented Coptis and Curcuma, the difference in color between the fabrics dyed with fermented dyeing material and those dyed with unfermented dyeing material was examined. The difference between the mordanted fabrics was also assessed using synthetic mordants and unmordanted fabrics. The color characteristics and the color difference value $(\Delta \mathrm{E})$ of silk according to the use of mordants and fermentation were measured and the results are presented in Tables 1 . To confirm the effect of the mordants on the fermented dye, the fabrics were pre-mordanted with aluminum acetate and copper acetate, and the dyeing characteristics were examined.

Table 1 show that the color characteristics of the fermented and unfermented dye were significantly different. Initially, the $b^{*}$ value increased significantly compared to the only control specimen without dyeing. In particular, Curcuma showed a higher $\mathrm{b}^{*}$ value than Coptis. This was the same as the increase in $\mathrm{C}$ value. For the change in $\mathrm{h}$ value, the undyed specimen showed $\mathrm{h}$ value of 100.3 but the dyed specimen with all types of conditions also showed a result from 80 and 93.6, regarding no significant change in hue. The $\Delta E$ of color difference value for all Curcuma dyed fabrics was between 44.06 and 63.96, which were a comparatively higher than Coptis (between 32.21 and 68.84). Silk has well known very good affinity for dyes and readily absorbs basic, acidic and direct dyes. In addition, berberine, which is the main component of Coptis, is a basic dye that can easily react to silk and also showed a significant change in its color value and $\Delta E$. A naked eye estimation confirmed that the silk fabric was dyed deep-dark yellow, which is the basic color of Coptis and Curcuma. 
Table 1. Color characteristics of Coptis and Curcuma dyed silk fabrics under various conditions

\begin{tabular}{|c|c|c|c|c|c|c|c|}
\hline Dyestuff & Treatment condition & $\mathrm{L}^{*}$ & $a^{*}$ & $b^{*}$ & $\mathrm{C}$ & $\mathrm{h}$ & $\Delta \mathrm{E}$ \\
\hline \multirow{7}{*}{ Coptis } & Control & 76.57 & -0.48 & 2.63 & 2.67 & 100.3 & 0 \\
\hline & Non -ferment & 60.89 & 9.09 & 61.78 & 62.44 & 81.63 & 61.94 \\
\hline & Non-Ferment \&Al mordant & 65.94 & 2.99 & 46.91 & 47.01 & 86.35 & 45.68 \\
\hline & Non-Ferment $\& \mathrm{Cu}$ mordant & 65.34 & 0.85 & 29.68 & 29.69 & 88.36 & 29.32 \\
\hline & Ferment & 60.53 & 10.59 & 64.46 & 65.33 & 80.67 & 68.84 \\
\hline & Ferment \& Al mordant & 65.09 & 2.17 & 45.57 & 45.62 & 87.28 & 44.53 \\
\hline & Ferment \& $\mathrm{Cu}$ mordant & 62.86 & 0.86 & 31.75 & 31.76 & 88.46 & 32.21 \\
\hline \multirow{6}{*}{ Curcuma } & Non -ferment & 70.28 & -3.80 & 66.19 & 66.30 & 93.29 & 63.96 \\
\hline & Non-Ferment \&Al mordant & 66.91 & 0.24 & 64.58 & 64.58 & 89.79 & 62.70 \\
\hline & Non-Ferment \&Cu mordant & 63.25 & 0.79 & 55.03 & 55.03 & 89.18 & 54.08 \\
\hline & Ferment & 67.76 & -3.54 & 56.29 & 56.40 & 93.60 & 54.47 \\
\hline & Ferment \& Al mordant & 69.73 & -2.24 & 50.55 & 50.60 & 92.54 & 48.44 \\
\hline & Ferment \& $\mathrm{Cu}$ mordant & 63.36 & -2.15 & 44.62 & 44.67 & 92.76 & 44.06 \\
\hline
\end{tabular}

Table 2. Color characteristics of Coptis and Curcuma dyed silk fabrics under various conditions after washing

\begin{tabular}{|c|c|c|c|c|c|c|c|}
\hline Dyestuff & Treatment condition & $\mathrm{L}^{*}$ & $\mathrm{a}^{*}$ & $\mathrm{~b}^{*}$ & $\mathrm{C}$ & $\mathrm{h}$ & $\Delta \mathrm{E}$ \\
\hline \multirow{7}{*}{ Coptis } & Control & 76.57 & -0.48 & 2.63 & 2.67 & 100.3 & 0 \\
\hline & Non -ferment & 69.70 & 0.24 & 43.96 & 43.96 & 89.69 & 21.76 \\
\hline & Non-Ferment \&Al mordant & 69.88 & 0.10 & 26.23 & 26.23 & 89.79 & 21.26 \\
\hline & Non-Ferment \&Cu mordant & 65.74 & 1.69 & 20.97 & 21.04 & 85.41 & 8.76 \\
\hline & Ferment & 57.73 & 1.38 & 37.78 & 37.80 & 87.91 & 28.37 \\
\hline & Ferment \& Al mordant & 66.37 & -0.28 & 21.90 & 21.90 & 90.73 & 28.83 \\
\hline & Ferment \& $\mathrm{Cu}$ mordant & 65.33 & 1.67 & 21.21 & 21.27 & 85.51 & 10.86 \\
\hline \multirow{6}{*}{ Curcuma } & Non -ferment & 68.36 & 3.56 & 22.80 & 23.08 & 81.13 & 44.05 \\
\hline & Non-Ferment \&Al mordant & 70.26 & 2.11 & 15.43 & 15.58 & 82.20 & 49.30 \\
\hline & Non-Ferment \&Cu mordant & 54.74 & 7.57 & 32.81 & 33.68 & 77.00 & 24.74 \\
\hline & Ferment & 68.48 & 1.50 & 18.47 & 18.53 & 85.37 & 38.16 \\
\hline & Ferment \& Al mordant & 68.99 & 1.20 & 14.20 & 14.25 & 85.17 & 36.51 \\
\hline & Ferment \& $\mathrm{Cu}$ mordant & 59.15 & 4.24 & 30.41 & 30.70 & 82.06 & 16.14 \\
\hline
\end{tabular}

3.6. Effect of fermentation and mordant to washing fastness by K/S

Table 3 presents the durability of silk according to changes in the surface color. In Table 3, the K/S of before and after washing on silk dyed with Coptis and Curcuma show a slighted creasing when the Coptis and Curcuma used after fermentation and $\mathrm{Cu}$ mordant, showing the K/S was $>6$ and 3.88, respectively. This suggests that the coloration with fermented plant dyeing is physically and structurally more stabilized than the unfermented plant dyeing. The increase in $\mathrm{K} / \mathrm{S}$ value was attributed to the increased likelihood of amide (-CONH-), hydroxyl (-OH) and thiol (-SH) groups, which are main functional groups of silk. This result is similar to the Ann's report (Ahn, 2004), where a large amount of nitrogen means a large amount of protein, and a large amount of carbon and hydrogen means that the organic molecules are composed of carbohydrates.
This indicates that the nitrogen in the protein of silk is functional groups that react with the dye. Therefore, a change in dyeing affinity was observed and the binding stability of silk with more functional groups became greater, showing better results in color analysis. Furthermore, the washing fastness of dyed silk after treatment washing reduced from 4 to below 4 , while dyed silk with fermented plant was not unsubstantial which occurred was not dye loss during repeated washing test. In contrast, the dyeing with Coptis obtained applying the $\mathrm{Cu}$ mordant suffered considerably lower dye loss after washing.

Generally, the poor light fastness of fabrics is the main problem with natural dyes, though the dyes fabrics look deep colored in appearance. The silk fabric has physico-chemically better durability or dyeability than cotton, but naturally not durable to light. Therefore, continuous exposure to light weakens silk faster than 
Table 3. K/S to before and after washing and the fastness to washing and light of Coptis and Curcuma dyed silk fabrics under various conditions

\begin{tabular}{|c|c|c|c|c|c|}
\hline \multirow{2}{*}{ Dyestuff } & \multirow{2}{*}{ Treatment condition } & \multicolumn{2}{|c|}{$\mathrm{K} / \mathrm{S}$ to washing } & \multirow{2}{*}{ Washing fastness } & \multirow{2}{*}{ Light fastness } \\
\hline & & Before & After & & \\
\hline \multirow{7}{*}{ Coptis } & Control & - & 0.36 & 4 & 1 \\
\hline & Non -ferment & 13.81 & 3.42 & $3-4$ & $1-2$ \\
\hline & Non-Ferment \&Al mordant & 5.11 & 1.67 & $2-3$ & $1-2$ \\
\hline & Non-Ferment $\& \mathrm{Cu}$ mordant & 2.66 & 2.11 & 3 & 2 \\
\hline & Ferment & 15.68 & 5.75 & 4 & 2 \\
\hline & Ferment \& Al mordant & 5.18 & 1.78 & $3-4$ & $1-2$ \\
\hline & Ferment \& $\mathrm{Cu}$ mordant & 3.36 & 2.21 & 4 & $1-2$ \\
\hline \multirow{6}{*}{ Curcuma } & Non -ferment & 11.25 & 0.36 & $2-3$ & $1-2$ \\
\hline & Non-Ferment \&Al mordant & 11.36 & 1.91 & $2-3$ & $1-2$ \\
\hline & Non-Ferment $\& \mathrm{Cu}$ mordant & 9.73 & 1.25 & 3 & 2 \\
\hline & Ferment & 8.67 & 5.51 & 4 & $1-2$ \\
\hline & Ferment \& Al mordant & 4.89 & 1.68 & $3-4$ & $1-2$ \\
\hline & Ferment \& $\mathrm{Cu}$ mordant & 6.01 & 1.36 & $3-4$ & 2 \\
\hline
\end{tabular}

either cotton or wool.

The light fastness of the unmordanted and mordanted silk fabrics dyed with Coptis and Curcuma by blue-wool scale at $63^{\circ} \mathrm{C}$ was shown in Table 3. These results could not be due to the dye affinity of Coptis and Curcuma compounds. On the other hand, the light fastness of silk with and without mordant was similar, grade 1-2 to 2. As previously mentioned Table 3 , the mordant treatment barely maintained wash fastness after fermentation and the light fastness also improved slightly only the cases of fermentation and pre-mordanting with the copper compound. This may be explained by the ability of copper to form a complex between both the silk and the dyeing site of Coptis and Curcuma. This complex might be more stable to light than other bonds. Consequently, a poor light fastness of the both these natural dyes in comparison with synthetic dyes is established beyond question. Nevertheless, the use of some natural additives, for instance, chitosan (Park et al., 2008), malt (Park, 2012a), and mineral water (Park, 2012b) can improve this problem of natural dyes.

\section{Conclusion}

This study evaluated the microorganisms used for the fermentation of dyes, Coptis and Curcuma, as well as the optimal culture conditions for the fermentation of dye powder and the growth of microorganisms. The dyeing property and durability of natural dyes fermented with cultured microorganisms and the unfermented natural dye were compared and the effects of the mordants used chemically were also examined. $P$. linteus was the optimal microorganism for the fermentation of Coptis and Curcuma, and MA medium was the optimal culture condition. In addition, when fungi rice bran were used as the fermenting agent, $32^{\circ} \mathrm{C}$ was determined to be the best fermenting temperature for both dyes. Regarding the dyeing properties of fermented natural dyes, silk was dyed very dark according to a naked eye examination, and the K/S value of silk presented 16, after the fermenting process. The K/S value of Curcuma dyed silk after washing was present quite satisfactory value as 5.51, while the non-fermented fabric were barely 0.365 . Although this study intended to maintain the washing and light fastness, both of 3-4 and a low fastness of 1 to 2 was observed, respectively. As a result, more studies using other fermenting conditions, microorganism and dyes would be needed in the future.

\section{Acknowledgements}

This study was funded by National Research Foundation of Korea (Grant No. NRF-2012R1A1A3012278).

\section{References}

Ahn, S. H. (2004). Fractionation of Glycosaminoglycans extracted from the Styelaclava Tunic. Unpublished master's thesis, Gyeongsang University, Jinju.

Cho, S. K. (2009). Dyeing of pig skin with Coptis chinensis Franch. The Korean Home Economics Association, 47(1), 85-91.

Cho, S. S., Song, H. S., \& Kim, B. H. (1997). The dyeability properties of some yellow natural dyeb (Part II) - Extracted from turmeric -. Journal of the Korean Society of Clothing and Textiles, 21(6), 10511059.

Chu Y. J., \& Soh, H. O. (1996). The study of curcuma longs L. Dyein. Journal of the Korean Society of Clothing and Textiles, 20(3), 429437.

Eum, J. S. (2012). Antimicrobial activity of Coptis chinensis and 
sophora flavescens against streptococcus mutans ATCC 25175. The Journal of the Korean Institute of Information and Communication Engineering, 16(2), 384-389.

Freile, M. L., Giannini, F., Pucci, G., Sturniolo, A., Rodero, L., Pucci, O., Balzareti, V., \& Enriz, R. D. (2003). Antimicrobial activity of aqueous extracts and of berberine isolated from Berberis heterophylla. Fitoterapia, 74(7-8), 702-705.

Han, S. Y., \& Choi, S. C. (2002). Antibacterial activity and identification of the active compound from tumeric extract. Textile Coloration \& Finishing, 14(1), 11-17.

Hong, M. G., Park, J. Y., Park, Y. M., Koo, K., Huh, M. W., \& Kim, S. S. (2006). A study on the measurement of colour fastness by $\mathrm{CCM}$ and new fastness formula. Textile Coloration \& Finishing, $18(2), 15-23$.

Hwang, E. K., Kim, M. S., Lee, D. S., \& Kim, K. B. (1998). Color development of natural dyes with some mordants - Combination dyeing of sappan wood and turmeric. Journal of the Korean Fiber Society, 35(8), 490-497.

Kim, K. S., Choung, M. G., \& Park, S. H. (2005). Quantitative determination and stability of curcuminoid pigments from turmeric(Curcuma Longa L.) root. Korean Journal Crop Science, 50(S), 211-215.

Lin, W. C., \& Lin, J. Y. (2011). Berberine down-regulates the Th1/Th2 cytokine gene expression ratio in mouse primary splenocytes in the absence or presence of lipopolysaccharide in a preventive manner. International Immunopharmacology, 11(12), 1984-1990.

Park, H. N., \& Cha, O. S. (1994). Research about Gardenia and Curcuma in yellow plant dye. Korean Living Science Rsearch, 12, 185-208.

Park, Y. M., Koo, K., Kim, S. S., \& Choe, J. D. (2008). Improving of colorfastness of PET fabrics with natural dye of extract of
Caesalpinia sappan L. wood extract and the effect of Chitosan and low temperature plasma. Journal of Applied Polymer Science, 109(1), 160-166.

Park, Y. M. (2012a) Investigation into the ecological and natural dyeing with medicinal plants after fermentation by NURUK and the effect of natural additives. Textile Coloration \& Finishing, 24(4), 260-269.

Park, Y. M. (2012b). Dyeability of fabrics by malt-fermented materials and mineral water mordanting - Effect of mordanting with Hwangsu (mineral water) of Youngcheon, Korea. Textile Coloration \& Finishing, 24(5), 270-280.

Ryu, S. R., Han, K. J., \& Doung, J. H. (2005). Separation and purification of effectiveness components from Ul Geum(Curcuma Longa) \& The test study of anticancer effects that Use Its. Applied Chemistry, 9(1), 69-72.

Siow, Y. L., Sarna, L., \& Karmin, O. (2011). Redox regulation in health and disease - Therapeutic potential of berberine. Food Research International, 44(8), 2409-2417.

Soh, H. O. (1998). A study on the stabitity and dyeing condition in the curcuma longa L. The Korea Society of Costume, 39, 79-89.

Yin, J., Ye, J., \& Jia, W. (2012). Effects and mechanisms of berberine in diabetes treatment. Acta Pharmaceutica Sinica B, 2(4), 327334.

Yu, J. H., \& Beun, Y. R. (2008). Biotechnology. Seoul: Hyoilbooks. Yu, T. J., Hong, J. H., Kim, Y. B., Lee, H., Kim, Y. E., Hwang, H. J., So, M. H., \& Lee, H. G. (1999). New Food Stuffs \& Microorganisms. Seoul: Munun Books.

(Received 20 June 2013; 1st Revised 5 August 2013; 2nd Revised 11 August 2013; 3rd Revised 19 August 2013;

Accepted 27 August 2013)

Copyright (C) The Society of Fashion and Textile Industry. 2013. This is an open access article distributed under the terms and conditions of the Creative Commons Attribution Non-Commercial license (http://creativecommons.org/licenses/by-nc/3.0/), which permits unrestricted non-commercial use, distribution, and reproduction in any medium, provided the original work is properly cited. 